\title{
The Cohesive Energy and Vibration Characteristics of Parallel Single-Walled Carbon Nanotubes
}

\author{
Jun Wang ${ }^{1}$, Yinfeng Chen ${ }^{2}$ and Peishi Yu ${ }^{2, *}$ \\ 1 School of Mechanical Technology, Wuxi Institute of Technology, Wuxi 214121, China; wangjun@wxit.edu.cn \\ 2 School of Mechanical Engineering, Jiangnan University, Wuxi 214122, China; yinfeng_chen@163.com \\ * Correspondence: psyu@jiangnan.edu.cn
}

check for updates

Citation: Wang, J.; Chen, Y.; Yu, P. The Cohesive Energy and Vibration Characteristics of Parallel Single-Walled Carbon Nanotubes. Molecules 2021, 26, 7470. https:// doi.org/10.3390/molecules26247470

Academic Editor:

Munkhbayar Batmunkh

Received: 8 November 2021

Accepted: 8 December 2021

Published: 10 December 2021

Publisher's Note: MDPI stays neutral with regard to jurisdictional claims in published maps and institutional affiliations.

Copyright: (c) 2021 by the authors. Licensee MDPI, Basel, Switzerland. This article is an open access article distributed under the terms and conditions of the Creative Commons Attribution (CC BY) license (https:// creativecommons.org/licenses/by/ $4.0 /)$.

\begin{abstract}
Based on the van der Waals (vdW) interaction between carbon atoms, the interface cohesive energy between parallel single-walled carbon nanotubes was studied using continuous mechanics theory, and the influence of the diameter of carbon nanotubes and the distance between them on the cohesive energy was analyzed. The results show that the size has little effect on the cohesive energy between carbon nanotubes when the length of carbon nanotubes is over $10 \mathrm{~nm}$. At the same time, we analyzed the cohesive energy between parallel carbon nanotubes with the molecular dynamics simulation method. The results of the two methods were compared and found to be very consistent. Based on the vdW interaction between parallel carbon nanotubes, the vibration characteristics of the two parallel carbon nanotube system were analyzed based on the continuous mechanical Euler-beam model. The effects of the vdW force between carbon nanotubes, the diameter and length of carbon nanotubes on the vibration frequency of carbon nanotubes was studied. The obtained results are helpful in improving the understanding of the vibration characteristics of carbon nanotubes and provide an important theoretical basis for their application.
\end{abstract}

Keywords: vdW interaction; single-walled carbon nanotube; cohesive energy; vibration

\section{Introduction}

For small structures on the scale of nanometers, the intermolecular van der Waals $(\mathrm{vdW})$ interaction can play a leading role in some cases [1]. Since their discovery, carbon nanotubes (CNTs) have shown great application prospects in various fields with their excellent physical and mechanical properties [2-5].

The molecular dynamics (MD) simulation software LAMMPS (Large-scale Atomic Molecular Massively Parallel Simulator) [6] has been widely used to predict the remarkable thermomechanical properties of CNTs, such as the influence of grain boundaries on the mechanical properties of polycrystalline carbon nanotubes [7] and the transversely isotropic thermal properties of carbon nanotubes containing vacancies [8,9]. The existing research results show that in a micro system composed of CNTs bundles, the van der Waals interaction between adjacent carbon tubes has a great impact on the mechanical behavior of the system [10-15].

With the influence of finite size and boundary effects, the internal vdW bonding energy has an important impact on the mechanical behavior of CNT bundle micro systems [16-18]. Therefore, clarifying the bond energy between tube bundles of finite size has important guiding significance for the design and application of microsystems [19-25].

In previous work, Zhao et al. obtained the analytical solution of the bonding energy per unit length of infinite parallel single-walled CNTs based on the continuous model, and analyzed the influence of CNT diameter on the bonding energy and the equilibrium distance of the interface [13]. However, due to the limited length of CNTs in actual microsystems, the scale effect of length on the cohesive energy between tubes needs to be further explored. 
Zhang et al. [17] prepared suspended single-walled CNT array devices and found that this structure has unique mechanical behavior. Based on the molecular mechanics model, Chang [18] proposed an anisotropic shell model to reveal the mechanical properties of CNTs, and studied the young's modulus, Poisson's ratio and radial breathing mode of single-walled CNTs, which laid a foundation for further study of the influence of the bonding energy between parallel carbon tubes on microsystems. Rueckes et al. [26] studied a suspended single-walled CNT array and found that the array has good characteristics of switchable and bi-stable device elements, and the mechanical stability of this structure is determined by the vdW interaction between single-walled CNTs. Wang and Hu further studied the thermodynamic vibration between monolayer graphene sheets based on the nonlocal elastic plate model [27]. Parallel CNT systems have prospective application as micromechanical systems.

For nano-mechanical systems, the shear deformation effect has been studied recently in the literature. Al-Furjan et al. presented the vibrational characteristics of a rotating orthotropic piezoelectric nanodisk [28]. Li et al. analyzed and tested the quasi-static compression and hygrothermal stability of BMI/CE co-cured composite lattice cylindrical shell [29]. Zhang et al. designed and fabricated an ultra-lightweight beam string structure made of carbon fibre-reinforced polymer (CFRP) composites [30]. Dai et al. investigated the vibrations of non-polynomial viscoelastic composite open-type shells under residual stresses [31]. Zhang et al. dealt with the vibration and low-velocity impact responses of functionally graded graphene nanoplatelet-reinforced composite panels on a viscoelastic foundation [32].

Considering the vdW interaction energy between the CNTs, it is expected that the vibration characteristics of the system are significantly different from those of an independent single tube, but this has not yet been clarified. Therefore, in this paper, the corresponding theoretical analyses and numerical simulations are carried out for the above problems. The paper is divided into three parts. Firstly, the van der Waals interaction between carbon atoms is analyzed, secondly, the bonding energy between finite size single-walled CNTs is calculated, based on the continuous mechanics theory, and finally, the vibration characteristics of a parallel single-walled bi-CNT system are analyzed.

\section{Quantification of the vdW Interaction between Carbon Atoms}

The vdW interaction energy between the carbon atoms is expressed by Equation (1) [13,33],

$$
V(r)=4 \varepsilon\left[\left(\frac{\sigma}{r}\right)^{12}-\left(\frac{\sigma}{r}\right)^{6}\right]
$$

where $r$ is the distance between atoms, $\varepsilon$ is the potential well depth with the value of $2.8437 \mathrm{MeV}$ and $\sigma$ is a reference value determined as $3.4 \AA$ the equivalent distance between the carbon atoms.

Based on Equation (1), the vdW energy variation with the distance between two carbon atoms is shown in Figure 1. For $r<r_{0}$, the repulsive force is dominant, defining the repulsive domain, whereas the attractive force is dominant for $r>r_{0}$, forming the attractive domain. The blue dash, red dot and black solid lines in Figure $1 \mathrm{~b}$ represent the repulsive, attractive and resultant forces between the two interacting atoms, respectively. The lowest point of the resultant force is the equilibrium position, which is determined by the energy-minimization through $\frac{\partial^{2} V(r)}{\partial r^{2}}=0$, leading to $r_{0}=3.8165 \AA$. 


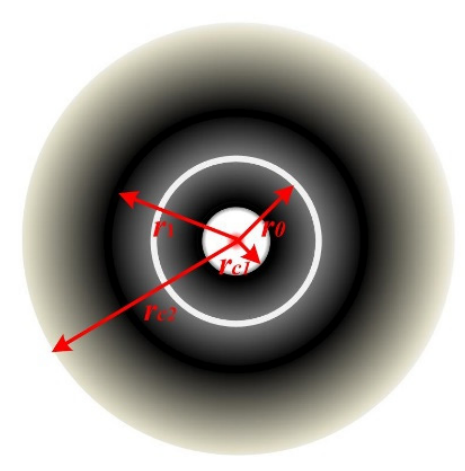

(a)

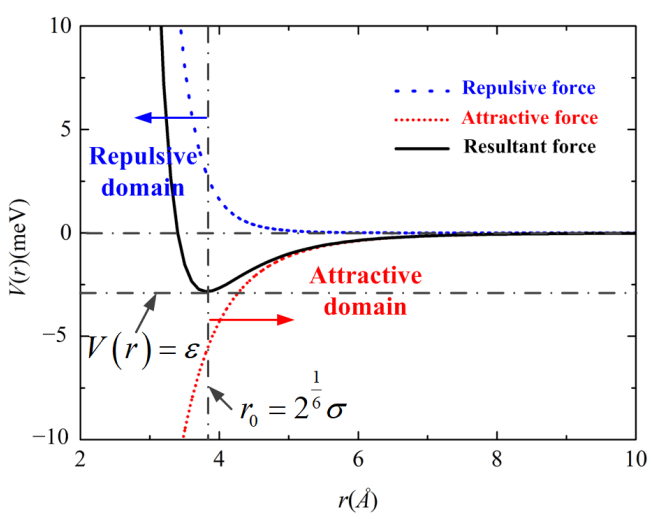

(b)

Figure 1. The vdW interaction between atoms: (a) the distribution diagram energy density surrounding the atom; (b) the interaction variation with the distance between two atoms.

\section{Cohesive Energy between Two Finite-Length Parallel CNTs}

The continuum model and coordinate system of two parallel single-walled CNTs are established as shown in Figure 2a. The radii of the CNTs are $r_{1}$ and $r_{2}$ respectively, and the shortest distance between parallel CNTs is $h$.

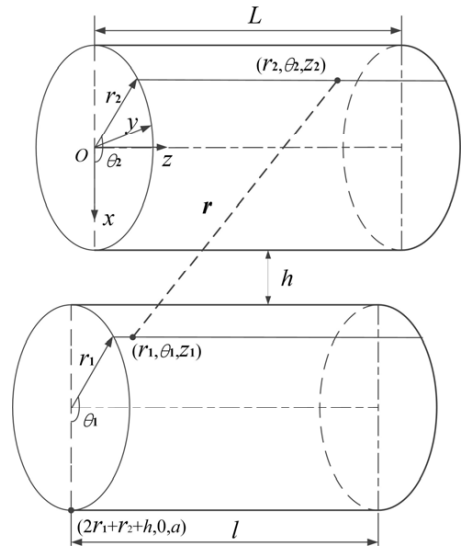

(a)
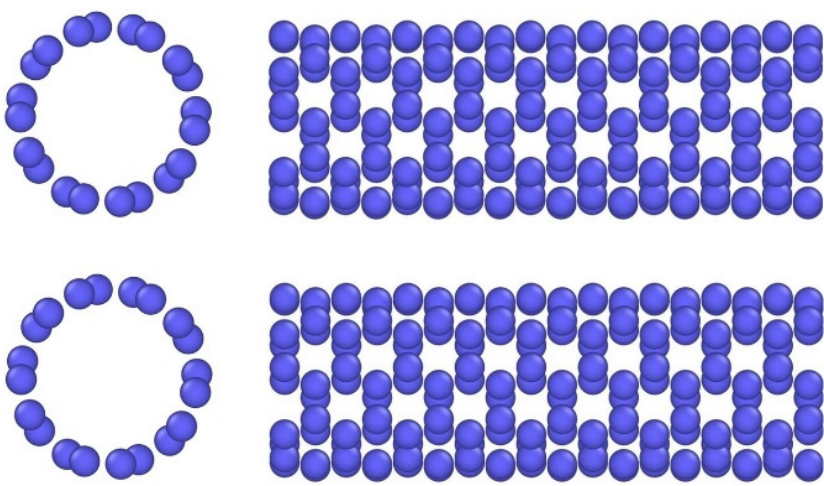

(b)

Figure 2. The (a) continuum model and coordinate system of two parallel single-walled CNTs and the (b) atom models of the MD simulations.

Molecular dynamics (MD) simulations were conducted using the LAMMPS software package [6] to verify the analytical model, as shown in Figure $2 b$. The adaptive intermolecular reactive empirical bond order (AIREBO) potential was used [34], which evaluates the covalent carbon-carbon bonding interaction by the well-established REBO potential, and the non-bonded van de Waals interaction was described by the 12-6 Lennard-Jones (LJ) potential $(\sigma=0.34 \mathrm{~nm}$ and $\varepsilon=0.0028 \mathrm{eV})[35,36]$. ReaxFF was mainly used for the chemical reaction atomic simulations, as the Tersoff potential cannot describe the non-bonded van de Waals interactions between CNTs. The AIREBO potential function with an LJ cut-off radius of $10.2 \AA$ was adopted in all the simulations [37,38]. The Polak-Ribiere version of the conjugated gradient algorithm [39] was used to optimize the initial positions of atoms. The temperature of system was controlled using Nose-Hoover thermal bath coupling [40,41] (coupling constant $0.1 \mathrm{ps}$, time step $0.5 \mathrm{fs}$ ) for $0.5 \mathrm{~ns}$. The time step used in the simulations was set at $0.5 \mathrm{fs}$. 
For the two parallel CNTs with finite length, the distribution along the horizontal direction is nonuniform, and can be determined by integration of the following Equation (2),

$$
\begin{aligned}
& \phi_{\text {total }}=\int_{A_{1}} \rho_{c} V(r) d A_{1} \int_{A_{2}} \rho_{c} d A_{2} \\
& =\rho_{c}^{2} \int_{0}^{2 \pi} r_{1} V(r) d \theta_{1} \int_{a}^{a+l} d z_{1} \int_{0}^{2 \pi} r_{2} d \theta_{2} \int_{0}^{L} d z_{2}
\end{aligned}
$$

where,

$$
\begin{aligned}
& r^{2}=\left(r_{1} \cos \theta_{1}+r_{1}+r_{2}+h-r_{2} \cos \theta_{2}\right)^{2}+ \\
& \left(r_{1} \sin \theta_{1}-r_{2} \sin \theta_{2}\right)^{2}+\left(z_{1}-z_{2}\right)^{2}
\end{aligned}
$$

and $\rho_{\mathrm{c}}$ is the area density of the atom number in the wall (number of atoms per unit area in the wall), $A_{1}$ and $A_{2}$ are the out-wall areas for the two parallel CNTs. Substituting the Equation (1) to Equation (2), leads to

$$
\phi_{\text {total }}=4 \varepsilon \sigma^{6} \rho_{c}^{2} r_{1} r_{2}\left[\sigma^{6} B_{1}-B_{2}\right]
$$

where $B_{1}$ is determined by,

$$
\begin{aligned}
B_{1} & =\int_{0}^{2 \pi} \frac{d \theta_{1} \int_{a}^{a+l} d z_{1} \int_{0}^{2 \pi} d \theta_{2} \int_{0}^{L} d z_{2}}{\left(\begin{array}{c}
\left(r_{1} \cos \theta_{1}+r_{1}+r_{2}+h-r_{2} \cos \theta_{2}\right)^{2} \\
+\left(r_{1} \sin \theta_{1}-r_{2} \sin \theta_{2}\right)^{2}+\left(z_{1}-z_{2}\right)^{2}
\end{array}\right)^{6}} \\
& =\frac{\pi^{2} \cdot l \cdot L}{4} \sum_{i=1}^{n} \sum_{j=1}^{n} \sum_{k=1}^{n} \sum_{p=1}^{n} w(i) w(j) w(k) w(p) H_{1}(t)
\end{aligned}
$$

in which,

$$
H_{1}(t)=\frac{1}{\left(\begin{array}{l}
\left(r_{1} \cos (\pi+\pi t(i))+r_{1}+r_{2}+h\right. \\
\left.-r_{2} \cos (\pi+\pi t(k))\right)^{2} \\
+\left(r_{1} \sin (\pi+\pi t(i)\right. \\
\left.-r_{2} \sin (\pi+\pi t(k))\right)^{2} \\
+\left(a+\frac{l}{2}+\frac{l}{2} t(j)-\frac{L}{2}-\frac{L}{2} t(p)\right)^{2}
\end{array}\right)^{6}}
$$

Similarly, $B_{2}$ is calculated by,

$$
\begin{aligned}
& B_{2}=\int_{0}^{2 \pi} \frac{d \theta_{1} \int_{a}^{a+l} d z_{1} \int_{0}^{2 \pi} d \theta_{2} \int_{0}^{L} d z_{2}}{\left[\left(r_{1} \cos \theta_{1}+r_{1}+r_{2}+h-r_{2} \cos \theta_{2}\right)^{2}+\left(r_{1} \sin \theta_{1}-r_{2} \sin \theta_{2}\right)^{2}+\left(z_{1}-z_{2}\right)^{2}\right]^{3}} \\
& =\frac{\pi^{2} \cdot l \cdot L}{4} \sum_{i=1}^{n} \sum_{j=1}^{n} \sum_{k=1}^{n} \sum_{p=1}^{n} w(i) w(j) w(k) w(p) H_{2}(t)
\end{aligned}
$$

where,

$$
H_{2}(t)=\frac{1}{\left(\begin{array}{l}
\left(r_{1} \cos (\pi+\pi t(i))+r_{1}+r_{2}+h\right. \\
\left.-r_{2} \cos (\pi+\pi t(k))\right)^{2} \\
+\left(r_{1} \sin (\pi+\pi t(i)\right. \\
\left.-r_{2} \sin (\pi+\pi t(k))\right)^{2} \\
+\left(a+\frac{l}{2}+\frac{l}{2} t(j)-\frac{L}{2}-\frac{L}{2} t(p)\right)^{2}
\end{array}\right)^{3}}
$$

in which, $t$ is the value corresponding to the given Gaussian point, $n$ is the number of Gauss points, and $W$ is the Gauss coefficient corresponding to the Gauss point.

For $a=0$ and $l=L$, the average cohesive energy per unit length from the vdW interactions is determined by,

$$
\phi_{\text {ave }}=\frac{\phi_{\text {total }}}{L}=\frac{4 \varepsilon \sigma^{6} \rho_{c}^{2} r_{1} r_{2}\left[\sigma^{6} A_{1}-A_{2}\right]}{L}
$$


The size-dependence of the cohesive energy between the two parallel CNTs is shown in Figure 3. It was found that the results obtained by the proposed analytical model for a pair of parallel CNTs with the length of $50 \AA$ show high agreement with those of MD simulations based on the models shown in Figure 2b. Additionally, the influence of the interval distance on the cohesive energy shows a non-monotonic tendency, which is quantified as shown in Figure 3. Here $h$ is the inter-wall distance between two parallel CNTs. The position changes with different CNT diameters. The results in Figure 3 suggest that the energy-optimized distance $h$ is independent of CNT diameters.

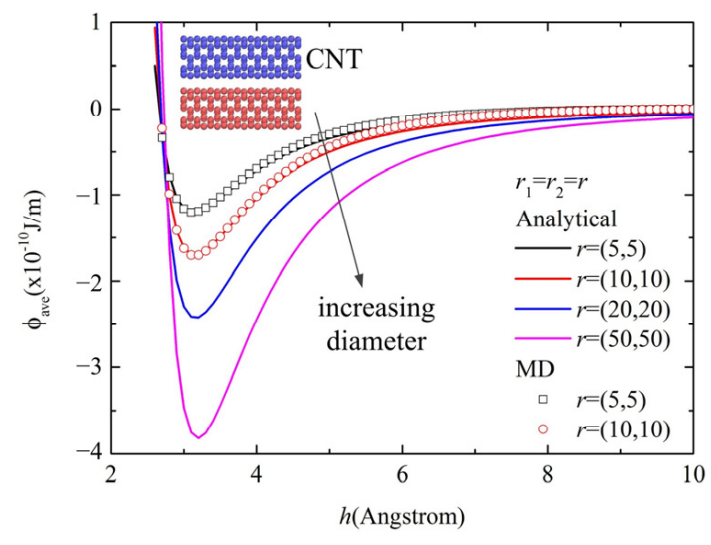

(a)

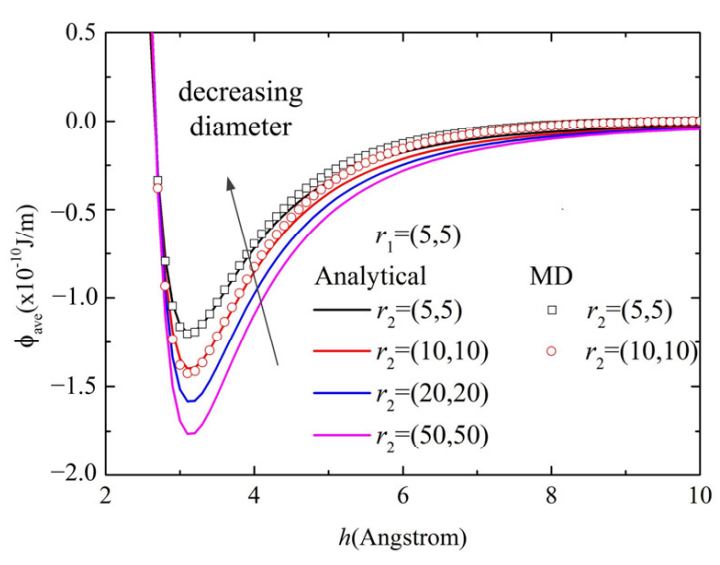

(b)

Figure 3. Size effect of cohesive energy of parallel CNTs with (a) the same diameter and (b) different diameters.

\section{The Vibration Characteristic of the Two Parallel CNTs}

The ends of the two parallel CNTs are fixed on substrates, as shown in Figure 4. The vibration characteristic of the two parallel CNTs is analyzed based on the continuum Euler beam model. Accordingly, the vibration equations of the system were obtained following [42],

$$
\begin{gathered}
E_{1} I_{1} \frac{\partial^{4} w_{n 1}}{\partial x^{4}}+\rho_{1} S_{1} \frac{\partial^{2} w_{n 1}}{\partial t^{2}}=K_{1}\left(w_{n 1}-w_{n 2}\right) \\
E_{2} I_{2} \frac{\partial^{4} w_{n 2}}{\partial x^{4}}+\rho_{2} S_{2} \frac{\partial^{2} w_{n 2}}{\partial t^{2}}=-K_{1}\left(w_{n 1}-w_{n 2}\right)
\end{gathered}
$$

where $E_{i}$ is the Young's modulus for the $i$ th CNT, here we use the well accepted value as $E_{1}=E_{2}=1 \mathrm{TPa}, I_{j}$ is the moment of the inertia of the $j$ th CNT and is defined as $I_{1}=I_{2}=$ $5.21 \times 10^{-38} \mathrm{~m}^{4}, \rho_{k}$ is the mass density of the $k$ th CNT and set as $\rho_{\mathrm{k}}=\rho_{\mathrm{k}}=1.3 \mathrm{~g} / \mathrm{cm}^{3}, S_{q}$ is the cross-section area of the $q$ th CNT and $K_{1}$ is the vdW interaction coefficient between parallel CNTs, determined by $K_{1}=\frac{\partial^{2} \phi_{\text {ave }}}{\partial h^{2}}$.

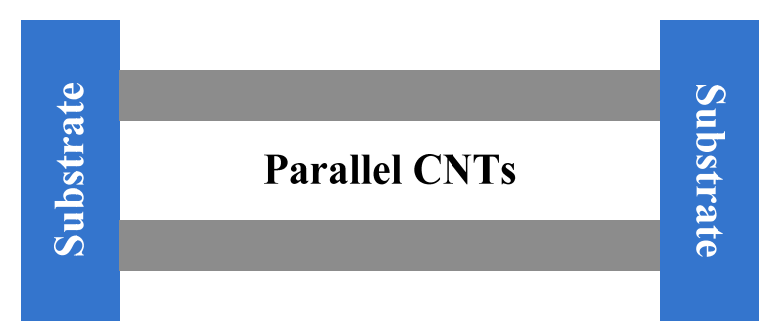

Figure 4. Continuum model for vibration analysis of parallel CNTs with constrained substrates.

To solve the above equation, the vibration mode functions were assumed to be,

$$
\begin{aligned}
& w_{n 1}=A_{n 1} \sin \left(\frac{n \pi x}{L}\right) e^{j \omega_{1} t} \\
& w_{n 2}=A_{n 2} \sin \left(\frac{n \pi x}{L}\right) e^{j \omega_{2} t}
\end{aligned}
$$

where $A_{n 1}$ and $A_{n 2}$ are the vibration amplitudes for the two CNTs. 
Substituting the Equation (10) to (9), we have,

$$
\begin{aligned}
& \omega_{n 1}^{2}=\frac{1}{2}\left(\alpha_{n}-\sqrt{\alpha_{n}^{2}-4 \beta_{n}}\right) \\
& \omega_{n 2}^{2}=\frac{1}{2}\left(\alpha_{n}+\sqrt{\alpha_{n}^{2}-4 \beta_{n}}\right)
\end{aligned}
$$

where,

$$
\begin{aligned}
\alpha_{n} & =\frac{E_{1} I_{1} \lambda_{n}^{4}+K_{1}}{\rho_{1} S_{1}}+\frac{E_{2} I_{2} \lambda_{n}^{4}+K_{1}}{\rho_{2} S_{2}} \\
\beta_{n} & =\frac{E_{1} I_{1} E_{2} I_{2} \lambda_{n}^{8}}{\rho_{1}^{2} S_{1} S_{2}}+K_{1} \lambda_{n}^{4} \frac{E_{1} I_{1}+E_{2} I_{2}}{\rho^{2} S_{1} S_{2}}
\end{aligned}
$$

in which $\lambda_{n}$ is determined by,

$$
\frac{d^{4} Y(x)}{d x^{4}}=\lambda_{n}^{4} Y(x), Y(x)=\sin \left(\frac{n \pi x}{L}\right)
$$

leading to $\lambda_{n}=n \pi / L$.

Figure 5 shows the resonant frequency and the amplitude ratio of the two parallel CNTs with the same diameter. The resonant frequency in Figure 5a increases nonlinearly with the tube diameter and reaches a minimum for a radius of $15 \AA$. The amplitude ratio reaches the lowest point for a radius of $40 \AA$, as shown in Figure $5 \mathrm{~b}$.

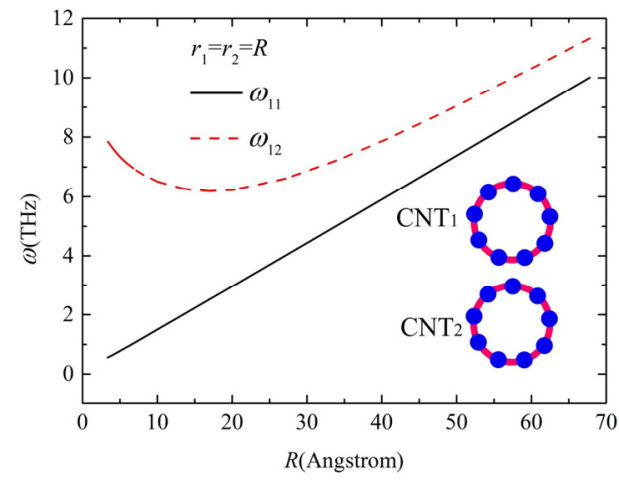

(a)

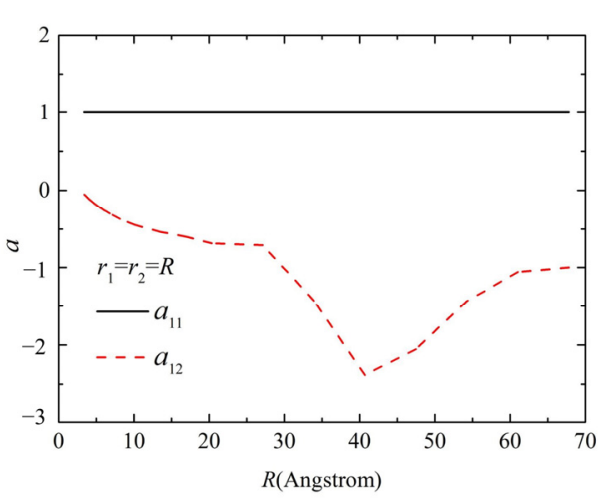

(b)

Figure 5. Vibration of the two parallel CNTs with the same diameter: (a) the resonance frequency and (b) amplitude ratio of CNTs.

\section{Discussion}

For two parallel CNTs with different tube diameters, the vibration frequencies are predicted by the analytical model as shown in Figure 6. The resonance frequency in Figure 6a for low-frequency vibration decreases with the increase in tube diameter. For high-frequency vibration in Figure $6 c$ the resonance frequency reaches the maximum value when $r_{2}=(20,20)$, which is among the several prediction results including $r_{2}=(5,5) \sim(50,50)$. The amplitude ratio in Figure $6 \mathrm{~b}$,d show remarkable dependence and significant nonlinearity with the change in the diameters of the two CNTs.

The influence of vibration modes (takes the first three orders into account) on the resonant frequency for the bi-CNT system with different tube diameters was obtained and is shown in Figure 7. It can be seen from Figure 7a,c that the order has a significant influence on the resonant frequency of carbon nanotubes, which show an increasing tendency in the resonant frequency with the increase in order. The amplitude ratio presents a decreasing dependence on the order, as shown in Figure $7 \mathrm{~b}, \mathrm{~d}$. This confirms that the system is nonlinear because the $\mathrm{vdW}$ interaction is nonlinear.

The proposed model focuses on the vibration of CNTs with large slenderness ratios. Thus, the deformation of the cross section is neglected in the continuum beam model. However, if the prerequisite of the large slenderness is not satisfied (for short CNT with large radius), the geometric nonlinearity would be influential on the vibration properties 
and cannot be neglected. The scope of applications of the continuum mechanics model at the nano scale is always an important topic and has been the subject of many studies in the field $[11,13,42]$. Here we proposed a beam model with the vdW interaction to analyze the dynamic behavior for a pair of parallel CNTs, and the high agreement of the results between the proposed beam model and the MD simulations indicates the high applicability of the continuum model. Therefore, we suggest that overall vibration modes for nano tubes (with a large ratio of length/radius $>5$ ) can be effectively analyzed by the continuum model for the dominant interaction (vdW, for instance). Since the CNTs are a promising material for constructing nano electromechanical systems, the proposed model provides an analytical model for designing the performance of CNT-based devices such as sensors, actuators, intelligent machines and so on.

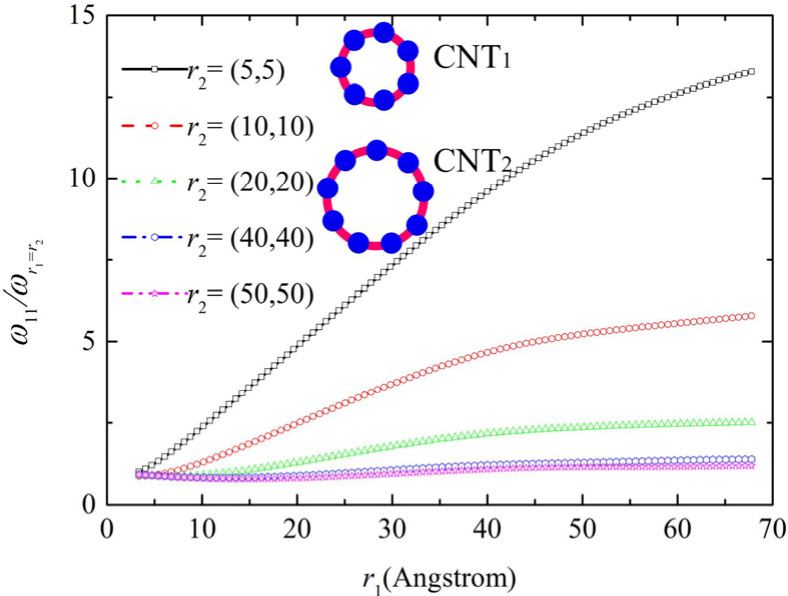

(a)

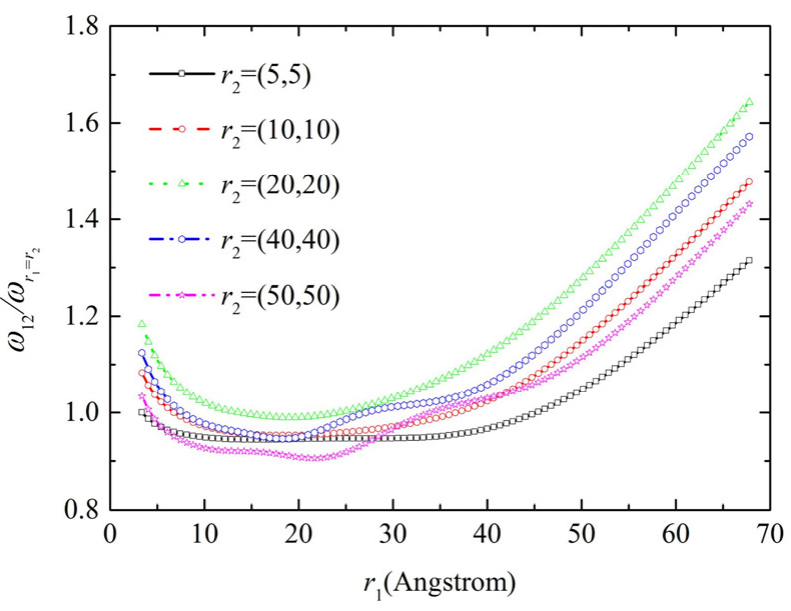

(c)

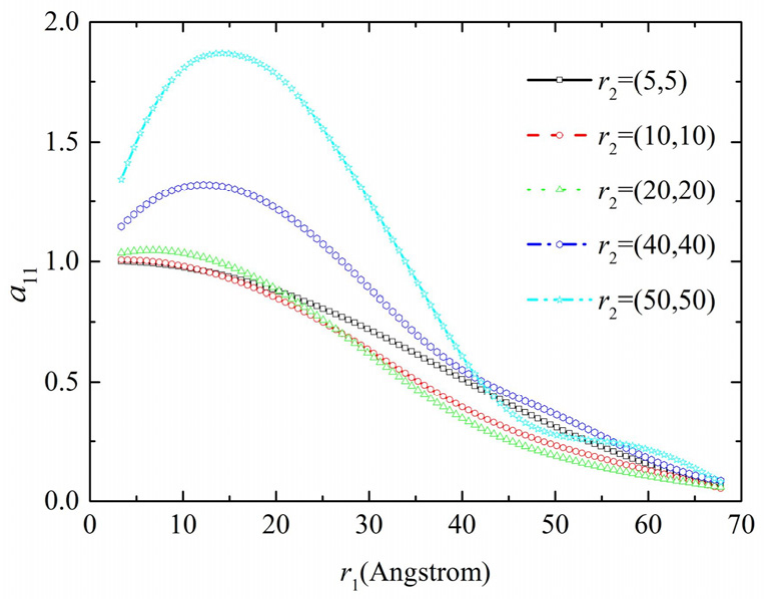

(b)

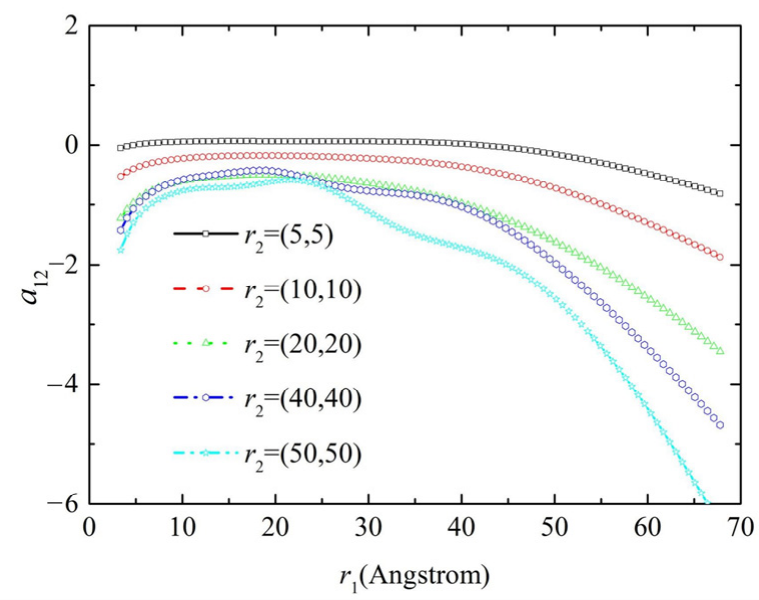

(d)

Figure 6. Vibration characteristic of the two parallel CNTs with different diameters: (a) resonance frequency under low frequency, (b) amplitude ratio of CNTs under low frequency, (c) resonance frequency under high frequency, (d) amplitude ratio of $\mathrm{CNTs}$ under high frequency. 


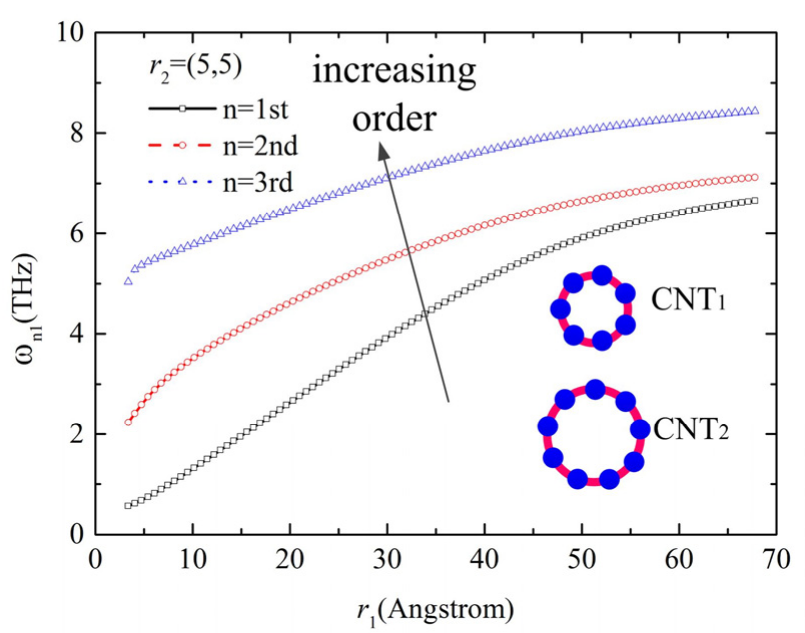

(a)

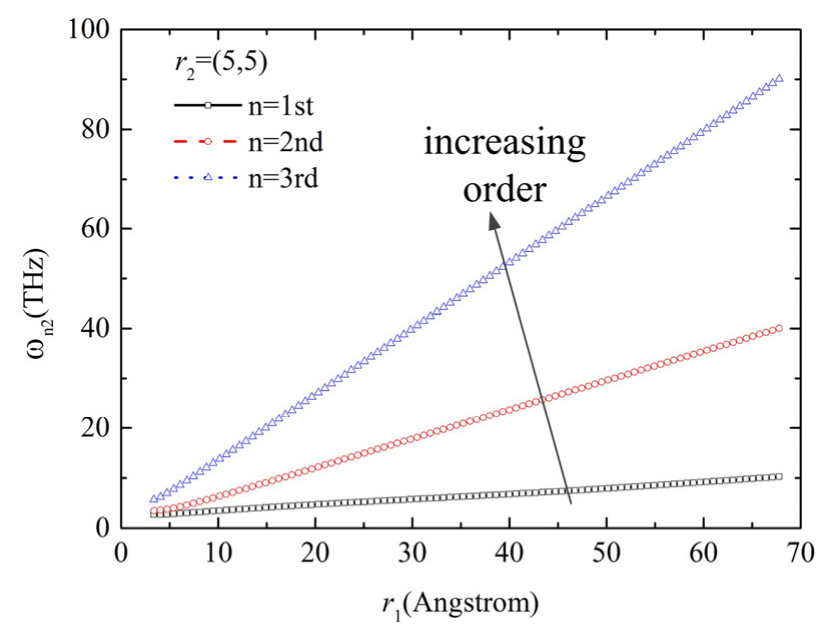

(c)

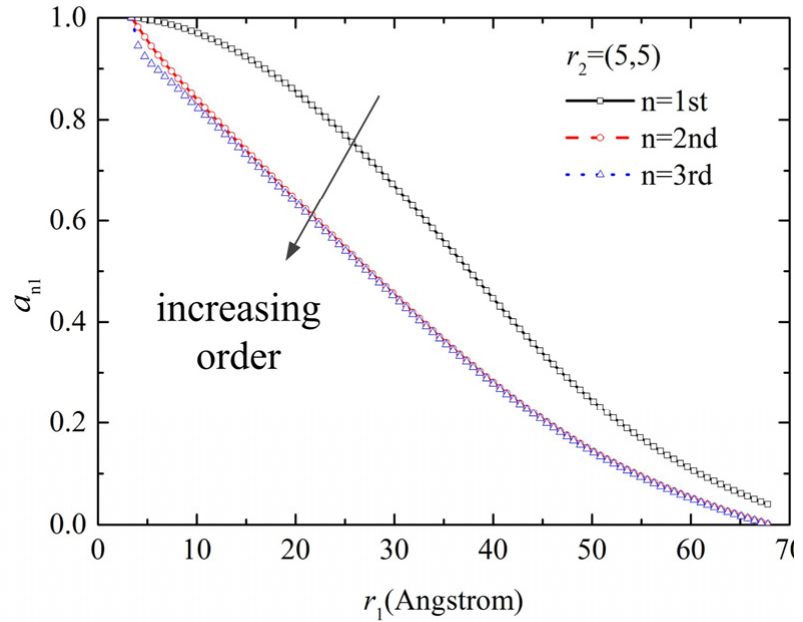

(b)

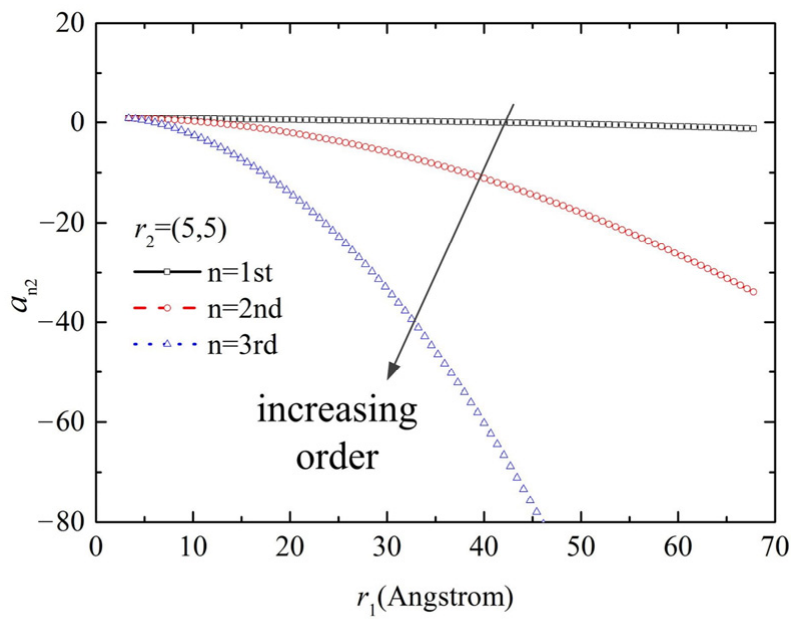

(d)

Figure 7. Effect of order on the vibration of CNTs with different diameters: (a) the increasing tendency for the resonant frequency with the increase in order under low frequency, (b) the decreasing dependence of amplitude ratio on the order under low frequency, (c) the increasing tendency for the resonant frequency with the increase in order under high frequency, (d) the decreasing dependence of amplitude ratio on the order under high frequency.

\section{Conclusions}

Based on the continuum mechanics model and the Gauss integral method, an analytical solution of the cohesive energy between parallel single-walled CNTs was obtained. On this basis, the vibration characteristics of a bi-CNT system were studied. Compared to the MD simulations, the continuum model is capable of providing more comprehensive results with a much lower computation cost. The main findings are concluded as follows:

(1) The analytical solutions for the vdW interaction between CNTs were obtained, which show remarkable nonlinear dependence on the interval distance between the tubes;

(2) The cohesive energy between adjacent CNTs varies nonlinearly with increasing tube diameter;

(3) The vibration frequency of the bi-CNT system is remarkably affected by the vibration mode and the tube diameter, which show different dependence on low-frequency and high-frequency vibrations. 
Author Contributions: Conceptualization, J.W. and P.Y.; methodology, Y.C. and P.Y.; software, Y.C.; validation, J.W. and P.Y.; writing-original draft preparation, J.W.; writing-review and editing, P.Y.; supervision, P.Y. All authors have read and agreed to the published version of the manuscript.

Funding: This research was funded by Young and Middle-aged Academic Leader of "Qinglan Project" of Universities in Jiangsu Province, Department of Education of Jiangsu Province [Jiangsu Teacher letter (2020) No. 10], and the Jiangsu Provincial Higher Vocational College Teacher Professional Leader High-end Research and Training [Jiangsu Higher Vocational College Training letter 2020GRFX090 (2020) No. 10.].

Institutional Review Board Statement: Not applicable.

Informed Consent Statement: Not applicable.

Data Availability Statement: Not applicable.

Conflicts of Interest: The authors declare no conflict of interest.

Sample Availability: Samples of the compounds are not available from the authors.

\section{References}

1. Koenig, S.P.; Boddeti, N.G.; Dunn, M.L.; Bunch, J.S. Ultrastrong adhesion of graphene membranes. Nat. Nanotechnol. 2011, 6, 543-546. [CrossRef] [PubMed]

2. Chang, T.C.; Gao, H.J. Size-dependent elastic properties of a single-walled carbon nanotube via a molecular mechanics model. J. Mech. Phys. Solids 2003, 51, 1059-1074. [CrossRef]

3. Slepchenkov, M.M.; Barkov, P.V.; Glukhova, O.E. Hybrid films based on bilayer graphene and single-walled carbon nanotubes: Simulation of atomic structure and study of electrically conductive properties. Nanomaterials 2021, 11, 1934. [CrossRef]

4. Shim, J.S.; Lee, G.H.; Cui, C.Y.; Beom, H.G. Mechanical behaviors of Si/CNT core/shell nanocomposites under tension: A molecular dynamics analysis. Nanomaterials 2021, 11, 1989. [CrossRef] [PubMed]

5. Wei, H.; Peng, Z.; Yang, C.; Tian, Y.; Sun, L.; Wang, G.; Liu, M. Three-Dimensional Au/Ag nanoparticle/crossed carbon nanotube sers substrate for the detection of mixed toxic molecules. Nanomaterials 2021, 11, 2026. [CrossRef] [PubMed]

6. Plimpton, S. Fast parallel algorithms for short-range molecular dynamics. J. Comput. Phys. 1995, 117, 1-19. [CrossRef]

7. Alian, A.R.; Meguid, S.A.; Kundalwal, S.I. Unraveling the influence of grain boundaries on the mechanical properties of poly-crystalline carbon nanotubes. Carbon 2017, 125, 180-188. [CrossRef]

8. Kothari, R.; Kundalwal, S.I.; Sahu, S.K. Transversely isotropic thermal properties of carbon nanotubes containing vacancies. Acta Mech. 2018, 229, 2787-2800. [CrossRef]

9. Kundalwal, S.I.; Choyal, V. Transversely isotropic elastic properties of carbon nanotubes containing vacancy defects using MD. Acta Mech. 2018, 229, 2571-2584. [CrossRef]

10. Carrella, A.; Brennan, M.J.; Waters, T.P. Static analysis of a passive vibration isolator with quasi-zero-stiffness characteristic. J. Sound Vib. 2007, 301, 678-689. [CrossRef]

11. Ru, C.Q. Effect of van der Waals forces on axial buckling of a double-walled carbon nanotube. J. Appl. Phys. 2000, 87, 7227-7231. [CrossRef]

12. Ru, C.Q. Axially compressed buckling of a doublewalled carbon nanotube embedded in an elastic medium. J. Mech. Phys. Solids 2001, 49, 1265-1279. [CrossRef]

13. He, X.Q.; Kitipornchai, S.; Liew, K.M. Buckling analysis of multi-walled carbon nanotubes: A continuum model accounting for van der Waals interaction. J. Mech. Phys. Solids 2005, 53, 303-326. [CrossRef]

14. Wang, C.Y.; Zhang, Y.Y.; Wang, C.M.; Tan, V.B.C. Buckling of carbon nanotubes: A literature survey. J. Nanosci. Nanotechnol. 2007, 7, 4221-4247. [CrossRef]

15. Lu, W.B.; Wu, J.; Song, J.; Hwang, K.C.; Jiang, L.Y.; Huang, Y. A cohesive law for interfaces between multi-wall carbon nanotubes and polymers due to the van der Waals interactions. Comput. Methods Appl. Mech. Eng. 2008, 197, 3261-3267. [CrossRef]

16. Zhao, J.; Jiang, J.-W.; Jia, Y.; Guo, W.; Rabczuk, T. A theoretical analysis of cohesive energy between carbon nanotubes, graphene and substrates. Carbon 2013, 57, 108-119. [CrossRef]

17. Zhang, J.; Liu, S.; Nshimiyimana, J.P.; Deng, Y.; Hou, G.; Chi, X.; Hu, X.; Zhang, Z.; Wu, P.; Wang, G.; et al. Wafer-Scale fabrication of suspended single-walled carbon nanotube arrays by silver liquid dynamics. Small 2017, 13, 1701218. [CrossRef]

18. Chang, T. A molecular based anisotropic shell model for single-walled carbon nanotubes. J. Mech. Phys. Solids 2010, 58, 1422-1433. [CrossRef]

19. Ghabussi, A.; Ashrafi, N.; Shavalipour, A.; Hosseinpour, A.; Habibi, M.; Moayedi, H.; Babaei, B.; Safarpour, H. Free vibration analysis of an electro-elastic GPLRC cylindrical shell surrounded by viscoelastic foundation using modified length-couple stress parameter. Mech. Based Des. Struct. Mach. 2021, 49, 738-762. [CrossRef]

20. Ghabussi, A.; Habibi, M.; NoormohammadiArani, O.; Shavalipour, A.; Moayedi, H.; Safarpour, H. Frequency characteristics of a viscoelastic graphene nanoplatelet-reinforced composite circular microplate. J. Vib. Control. 2021, 27, 101-118. [CrossRef] 
21. Safarpour, M.; Ghabussi, A.; Ebrahimi, F.; Habibi, M.; Safarpour, H. Frequency characteristics of FG-GPLRC viscoelastic thick annular plate with the aid of GDQM. Thin-Walled Struct. 2020, 150, 106683. [CrossRef]

22. Habibi, M.; Darabi, R.; de Sa, J.C.; Reis, A. An innovation in finite element simulation via crystal plasticity assessment of grain morphology effect on sheet metal formability. Proc. Inst. Mech. Eng. Part L J. Mater. Des. Appl. 2021, 235, 1937-1951. [CrossRef]

23. Peng, D.; Chen, S.; Darabi, R.; Ghabussi, A.; Habibi, M. Prediction of the bending and out-of-plane loading effects on formability response of the steel sheets. Arch. Civ. Mech. Eng. 2021, 21, 1-13. [CrossRef]

24. Shariati, A.; Jung, D.W.; Mohammad-Sedighi, H.; Żur, K.K.; Habibi, M.; Safa, M. Stability and Dynamics of Viscoelastic Moving Rayleigh Beams with an Asymmetrical Distribution of Material Parameters. Symmetry 2020, 12, 586. [CrossRef]

25. Ebrahimi, F.; Hashemabadi, D.; Habibi, M.; Safarpour, H. Thermal buckling and forced vibration characteristics of a porous GNP reinforced nanocomposite cylindrical shell. Microsyst. Technol. 2020, 26, 461-473. [CrossRef]

26. Rueckes, T.; Kim, K.; Joselevich, E.; Tseng, G.Y.; Cheung, C.-L.; Lieber, C.M. Carbon nanotube-based nonvolatile random access memory for molecular computing. Science 2000, 289, 94-97. [CrossRef] [PubMed]

27. Wang, L.; Hu, H. Thermal vibration of a rectangular single-layered graphene sheet with quantum effects. J. Appl. Phys. 2014, 115, 233515. [CrossRef]

28. Al-Furjan, M.S.H.; Dehini, R.; Khorami, M.; Habibi, M.; Jung, D.W. On the dynamics of the ultra-fast rotating cantilever orthotropic piezoelectric nanodisk based on nonlocal strain gradient theory. Compos. Struct. 2021, 255, 112990. [CrossRef]

29. Li, S.; Chen, Z.; Wang, Y.; Huang, Y.Y.; Yu, T. Quasi-static compression and hygrothermal stability of BMI/CE co-cured composite lattice cylindrical shell. Compos. Struct. 2021, 257, 113130. [CrossRef]

30. Zhang, J.; Zhou, P.; Guan, C.; Liu, T.; Kang, W.-H.; Feng, P.; Gao, S. An ultra-lightweight CFRP beam-string structure. Compos. Struct. 2021, 257, 113149. [CrossRef]

31. Dai, Z.; Zhang, L.; Bolandi, S.Y.; Habibi, M. On the vibrations of the non-polynomial viscoelastic composite open-type shell under residual stresses. Compos. Struct. 2021, 263, 113599. [CrossRef]

32. Zhang, L.; Chen, Z.; Habibi, M.; Ghabussi, A.; Alyousef, R. Low-velocity impact, resonance, and frequency responses of FG-GPLRC viscoelastic doubly curved panel. Compos. Struct. 2021, 269, 114000. [CrossRef]

33. Jiang, L.Y.; Huang, Y.; Jiang, H.; Ravichandran, G.; Gao, H.; Hwang, K.C.; Liu, B. A cohesive law for carbon nanotube/polymer interfaces based on the van der Waals force. J. Mech. Phys. Solids 2006, 54, 2436-2452. [CrossRef]

34. Brenner, D.W.; Shenderova, O.A.; Harrison, J.A.; Stuart, S.J.; Ni, B.; Sinnott, S.B. A second-generation reactive empirical bond order (REBO) potential energy expression for hydrocarbons. Mater. Sci. 2002, 14, 783-802. [CrossRef]

35. González Noya, E.; Srivastava, D.; Chernozatonskii, L.A.; Menon, M. Thermal conductivity of carbon nanotube peapods. Phys. Rev. B 2004, 70, 115416. [CrossRef]

36. Xu, Z.; Buehler, M.J. Geometry controls conformation of graphene sheets: Membranes, ribbons, and scrolls. ACS Nano 2010, 4, 3869-3876. [CrossRef] [PubMed]

37. Wei, N.; Fan, Z.; Xu, L.-Q.; Zheng, Y.-P.; Wang, H.-Q.; Zheng, J.-C. Knitted graphene-nanoribbon sheet: A mechanically robust structure. Nanoscale 2012, 4, 785-791. [CrossRef]

38. Chen, Y.; Zhang, Y.; Cai, K.; Jiang, J.; Zheng, J.-C.; Zhao, J.; Wei, N. Interfacial thermal conductance in graphene/black phosphorus heterogeneous structures. Carbon 2017, 117, 399-410. [CrossRef]

39. Polak, E. Optimization: Algorithms and Consistent Approximations; Springer: Berlin/Heidelberg, Germany, 1997.

40. Nosé, S. A unified formulation of the constant temperature molecular dynamics methods. J. Chem. Phys. 1984, 81, 511-519. [CrossRef]

41. Hoover, W.G. Canonical dynamics: Equilibrium phase-space distributions. Phys. Rev. A 1985, 31, 1695. [CrossRef]

42. Yoon, J.; Ru, C.Q.; Mioduchowski, A. Vibration of an embedded multiwall carbon nanotube. Compos. Sci. Technol. 2003, 63, 1533-1542. [CrossRef] 